\title{
Extraction of Chromium(III) and Chromium(VI) Species from Solid Matrices Using Green Solvent Supercritical Carbon Dioxide
}

\author{
Joanna Shaofen WANG* and Kong-Hwa CHIU**† \\ * Department of Chemistry, University of Idaho, Moscow, ID 83844-2343, USA \\ **Department of Applied Science, National Hualien University of Education, Hualien, Taiwan 970, ROC
}

\begin{abstract}
Supercritical fluid extraction (SFE) provides an environmentally green technique to decontaminate chromium species from solid matrices using supercritical fluid carbon dioxide $\left(\mathrm{ScCO}_{2}\right)$. Methanol and a small amount of water were found to significantly improve the extraction efficiency. The fluorinated chelating agent lithium bis(trifluoroethyl)dithiocarbamate (LiFDDC) was effective in removing $\mathrm{Cr}$ ions in methanol-modified $\mathrm{CO}_{2}$ via in situ chelation/SFE technique. This paper indicates that the extraction efficiencies of $\mathrm{Cr}(\mathrm{III})$ and $\mathrm{Cr}(\mathrm{VI})$ from solid matrices can be greatly increased to more than $92 \%$ in the presence of a small amount of water, using $5 \%$ methanol-modified $\mathrm{CO}_{2}$ containing LiFDDC as an extractant. Chromium species in a wood waste sample in the form of chromated copper arsenate (CCA) can be extracted, but the extraction efficiency is not as good as expected, possibly due to the complications of the chemistry of $\mathrm{Cr}$ species in different oxidation states and to matrix effects.
\end{abstract}

(Received January 9, 2007; Accepted May 28, 2007; Published November 10, 2007)

Determination and removal of heavy metals from natural samples are the essential requirements in a variety of environmental investigations. ${ }^{1}$ Chromium speciation has attracted great attention in scientific communities due to the toxic nature of $\mathrm{Cr}(\mathrm{VI})$ relative to $\mathrm{Cr}(\mathrm{III}) .^{2}$ Hexavalent chromium is considered to be extremely toxic and carcinogenic. In aqueous solution, trivalent chromium is difficult to extract due to its strong hydration by water molecules. This strong hydration prohibits the access of chelating agents to the metal centers in conventional solvent extraction. ${ }^{3,4}$ With a selective chelating agent and under specific conditions, $\mathrm{Cr}(\mathrm{VI})$ and $\mathrm{Cr}$ (III) can be separated from aqueous solutions by solvent extraction. ${ }^{5}$ For example, EPA methods 218.3 and 218.4 indicate that $\mathrm{Cr}(\mathrm{VI})$ can be extracted by ammonium pyrrolidinedithiocarbamate (APDC) into isobutyl methyl ketone (IBMK) at $\mathrm{pH} 2.8 .{ }^{6}$ In the EPA's methods, $\mathrm{Cr}(\mathrm{III})$ is initially oxidized to $\mathrm{Cr}(\mathrm{VI})$ by $\mathrm{KMnO}_{4}$, followed by extraction with APDC. The amount of $\mathrm{Cr}(\mathrm{III})$ is calculated based upon the difference of total $\mathrm{Cr}$ minus $\mathrm{Cr}(\mathrm{VI})$ removed. Studies also indicate that $\mathrm{Cr}(\mathrm{VI})$ reacts with ammonium pyrrolidinedithiocarbamate ligand to form two products, $\mathrm{Cr}(\mathrm{PDC})_{2}(\mathrm{OPDC})$ and $\mathrm{Cr}(\mathrm{PDC})_{3}$. The former involves coordination with two normal dithiocarbamate ligands and one dithioperoxycarbamate ligand. The latter was formed with three PDC ligands. ${ }^{5}$ The complexes formed by $\mathrm{Cr}(\mathrm{VI})$ and $\mathrm{Cr}(\mathrm{III})$ individually with sodium diethyldithiocarbamate (NaDDC) give different chemical structures. For example, Tande et al. ${ }^{3}$ and Hope et al. ${ }^{8}$ reported that $\mathrm{Cr}(\mathrm{III})$ forms a $\mathrm{Cr}(\mathrm{DDC})_{3}$ complex with $\mathrm{NaDDC}$, whereas $\mathrm{Cr}(\mathrm{VI})$ is first reduced by the ligand and then forms two different complexes $\mathrm{Cr}(\mathrm{DDC})_{3}$ and $\mathrm{Cr}(\mathrm{DDC})_{2}(\mathrm{ODDC})$, where ODDC represents an oxygen atom inserted between the

$\doteqdot$ To whom correspondence should be addressed.

E-mail: ckh@mail.nhlue.edu.tw metal ion and one of the sulfur atoms. ${ }^{3,8}$ These two complexes formed by $\mathrm{Cr}(\mathrm{VI})$ with NaDDC can be separated by HPLC. . $^{3,9}$ Extraction of $\mathrm{Cr}(\mathrm{III})$ by APDC occurs at higher $\mathrm{pH}$ but appears to have a very low efficiency at room temperature. The nonextractability of $\mathrm{Cr}$ (III) by solvent extraction is ascribed to the fact that $\mathrm{Cr}$ (III) is strongly hydrated and the displacement of coordinated water molecules by dithiocarbamate ligand is kinetically difficult. ${ }^{3,7}$ The complexes formed by $\mathrm{Cr}(\mathrm{VI})$ or $\mathrm{Cr}$ (III) with $\mathrm{NaDDC}$ have different chemical structures. Of particular interest to analytical chemists is the possibility of applying in situ chelation/SFE technique for the extraction metal species $\mathrm{Cr}(\mathrm{VI})$ and $\mathrm{Cr}(\mathrm{III})$ from solid materials. Only a few papers have been reported regarding the investigation of $\mathrm{Cr}$ extraction with $\mathrm{ScCO}_{2}$. Supercritical fluid extraction has become an attractive alternative to conventional solvent extraction from environmental samples. There are several advantages from an environmental standpoint, rooted in the characteristics of carbon dioxide being nontoxic, nonflammable, and having the potential for recycling. ${ }^{10-12}$ The in situ chelation/SFE technology presented here shows advantages over conventional solvent extraction methods, in which it greatly minimizes the organic solvent generation in decontamination processes. Carbon dioxide is an excellent solvent for SFE due to its moderate critical constants $\left(\mathrm{Temp} .=31^{\circ} \mathrm{C}\right.$ and $P_{\mathrm{c}}=7.4 \mathrm{MPa}$ ), inertness, and tunable solvating strength. Solutes can often be separated from the supercritical fluid by simply venting the benign $\mathrm{CO}_{2}$ into the atmosphere, leaving pure solutes behind. Moreover, supercritical $\mathrm{CO}_{2}$ can easily penetrate and diffuse into small pores of solid matrices and effectively remove organic and inorganic species.

The following factors are important for effective extraction of metal species using $\mathrm{ScCO}_{2}$ : the solubility of the chelating agent, the solubility and stability of the metal complex, the pressure, the temperature, and the chemical forms of metal species and 
sample matrix..$^{13-15}$ Direct extraction of metal ions by $\mathrm{ScCO}_{2}$ is highly inefficient because of the charge neutralization requirement that causes weak solvent-solute interactions. When metal ions are bound to organic ligands, however, they become quite soluble in $\mathrm{ScCO}_{2}$. In 1992, Laintz et al. ${ }^{13}$ first reported the extraction of $\mathrm{Cu}(\mathrm{II})$ from liquid and solid materials using $\mathrm{ScCO}_{2}$ containing lithium bis(trifluoroethyl)dithiocarbamate (LiFDDC) as an extractant. Using 8-hydroquinoline as a chelating agent, $\mathrm{Cr}(\mathrm{III})$ has been successfully removed from solid samples in $\mathrm{ScCO}_{2}{ }^{16}$ Foy and Pacey extracted $\mathrm{Cr}(\mathrm{VI})$ using two different dithiocarbamate derivatives LiFDDC and tetrabutylammonium dibutyldithiocarbamate to allow extraction of $1 \mathrm{ppm}$ of $\mathrm{Cr}(\mathrm{VI})$ from a solid matrix with a recovery of $88.4 \% .{ }^{17}$ Kersch and coworkers $^{18}$ demonstrated SFE of heavy metals including $\mathrm{Cr}$ from fly ash in $\mathrm{ScCO}_{2}$ using bis(2,4,4-trimethylpentyl)monothiophosphinic acid (trade name: Cyanex 302). Arancibia et al. ${ }^{19}$ successfully removed and quantified the amount of $\mathrm{Cr}$ in urine samples in a form of $\mathrm{Cr}(\mathrm{acac})_{3}$ (chromium acetylacetonate) complex using SFE and chromatography. Quantitative extraction was achieved at $20.2 \mathrm{MPa}$ and $120^{\circ} \mathrm{C}$ with $2 \mathrm{~mL}$ methanol (as a modifier) and $30 \mathrm{~min}$ static extraction, followed by 5 min dynamic extraction. The paper presented here describes in situ chelation/SFE of direct extraction of $\mathrm{Cr}(\mathrm{III})$ and $\mathrm{Cr}(\mathrm{VI})$ from solid matrices using methanol-modified $\mathrm{ScCO}_{2}$-containing LiFDDC. Variables which influence the SFE extractions, such as extraction time, water, modifier, oxidation states of $\mathrm{Cr}$, pressure, and temperature are discussed. Removal of $\mathrm{Cr}$ from environmentally real samples using $\mathrm{ScCO}_{2}$ can reduce the leachable toxic heavy metals released into the environment. Extraction of $\mathrm{Cr}(\mathrm{III})$ and $\mathrm{Cr}(\mathrm{VI})$ is feasible using in situ chelation/SFE technique in $\mathrm{ScCO}_{2}$; such extarction is kinetically difficult in traditional solvent extraction.

\section{Experimental}

\section{Reagents and materials}

Lithium bis(trifluoroethyl)dithiocarbamate was synthesized according to the procedure outlined in the literature. ${ }^{20}$ The starting material, bis(trifluoroethyl)amine, was obtained from PCR Chemicals (Gainesville, FL). Other chemicals used in the synthesis including $n$-butyllithium ( $2.5 \mathrm{M}$ in hexane), carbon disulfide, and isopentane were obtained from Aldrich Chemical Co. (Milwaukee, WI). All other reagents and solvents used in this study were of analytical grade and were obtained from Aldrich Chemical Company or Baxter Scientific (McGraw Park, IL). Deionized water from a Millipore Milli-Q system (Bedford, MA) was used for the preparation of all aqueous solutions. $\mathrm{Cr}(\mathrm{III})$ and $\mathrm{Cr}(\mathrm{VI})$ in atomic absorption spectroscopy (AAS) standards (1000 ppm) were purchased from EM Chemical. Wood samples (from a weathered telephone pole), containing chromated copper arsenate (CCA) from wood treatment processes, were obtained from a forest product laboratory, Department of Forestry, University of Idaho, USA. Each sample was dried, ground, and homogenized completely. The size of the pieces of CCA-treated wood sawdust was approximately 40 mesh.

\section{Apparatus}

All experiments were performed with a laboratory-built supercritical fluid extraction apparatus. SFC-grade $\mathrm{CO}_{2}$ and $5 \%$ methanol modified $\mathrm{CO}_{2}$ were obtained from Scott Speciality Gases (Plumsteadville, PA). The fluid was delivered to the SFE system using a microprocessor-controlled high-pressure pump
(Haskel Inc., Burbank, CA). The pressure of the system was monitored to \pm 5 psi using a Setra Systems (Acton, MA) pressure transducer. The extractor consisted of an inlet valve (Supelco, Bellefonte, PA) and an outlet valve connected to a stainless-steel 3.47-mL commercial extraction cell (Dionex, Sunnyvale, CA). The extraction cell was placed in an oven whose temperature was controlled by a thermostat. Fused-silica tubing (Dionex, $50 \mu \mathrm{m}$ i.d. and $20 \mathrm{~cm}$ in length) was used as the pressure restrictor for the exit gas. Static and dynamic extractions were performed and controlled by the outlet and inlet high-pressure valves.

Non-destructive instrumental neutron activation analysis (NAA) was used to identify and measure the quantities of $\mathrm{Cr}$ species. The samples and standards were irradiated in a $1 \mathrm{MW}$ TRIGA nuclear reactor at a steady flux of $6 \times 10^{12} \mathrm{n} \mathrm{cm}^{-2} \mathrm{~s}^{-1}$ for $1 \mathrm{~h}$. After cooling for a couple of days, the activated samples and standards were counted on a large-volume ORTEC $\mathrm{Ge}(\mathrm{Li})$ detector with a resolution (FWHM) of $2.3 \mathrm{keV}$ at the $1332 \mathrm{keV}$ ${ }^{60} \mathrm{Co}$ peak. The detector has an efficiency of $15 \%$ relative to a $3 \times 3 \mathrm{NaI}$ crystal. The $\gamma$-rays of $\mathrm{Cr}$ were emitted at $320 \mathrm{keV}$, with a half live of 27.8 days. A $\mathrm{Ge}(\mathrm{Li})$ detector was used to count ${ }^{51} \mathrm{Cr}$ activities at $320 \mathrm{keV} \gamma$-peak. The detector output was fed to a Nuclear Data 4096-channel pulse-height analyzer and MCB software. The details of the NAA procedures are given elsewhere. $^{21}$

\section{Extraction procedures}

For the extraction of $\mathrm{Cr}(\mathrm{III})$ and $\mathrm{Cr}(\mathrm{VI})$ species, two solid matrices were employed. (1) An aliquot containing $10 \mu \mathrm{g}$ of $\mathrm{Cr}(\mathrm{III})$ or $\mathrm{Cr}(\mathrm{VI})$ ion solution prepared from AAS standard was spiked onto cellulose-based filter paper (Whatman $42,0.7 \mathrm{~cm} \times$ $2 \mathrm{~cm}$ in size). The piece of filter paper was then inserted into the open end of a glass tube $(3 \mathrm{~cm}$ in length and $0.65 \mathrm{~cm} \mathrm{o.d.)}$ where a small amount of glass fiber was mounted previously. (2) To a glass tube which contained $200 \mathrm{mg}$ of sand grains held in place by a small amount of glass fiber, an aliquot containing $10 \mu \mathrm{g}$ of $\mathrm{Cr}$ sample was spiked. For both cases, $10 \mu \mathrm{L}$ of deionized water were then added directly afterwards. The head of the glass tube was also plugged with a piece of glass wool and then connected into a bulb-shaped glass tube $(2 \mathrm{~cm}$ in length, $0.60 \mathrm{~cm}$ o.d.) in which $50 \mathrm{mg}$ of LiFDDC ligand was loaded. Because the o.d. of the end of ligand tube is slightly smaller than the i.d. of the sample tube, the former can be partially inserted into the latter. These tubes were all mounted inside the extraction cell, which was then placed in the oven. The temperature and pressure were then increased to the desired values for extraction. Neat $\mathrm{CO}_{2}$ or $5 \%$ methanol modified $\mathrm{CO}_{2}$ was used in this study. The extracted $\mathrm{Cr}$ complexes were trapped by chloroform that was placed in two glass cylinders (1.2 cm i.d. and $10 \mathrm{~cm}$ in length) connected in series.

Initial retentions of $\mathrm{Cr}, \mathrm{Cu}$, and $\mathrm{As}$ in the wood sample are $18223 \pm 250,9425 \pm 180$, and $20054 \pm 290$ ppm, respectively, according to our elemental analyses from ICP-AES. For the real sample, wood from a weathered telephone pole containing CCA from wood treatment processes was used. A 50-mg amount of wood sample was tested with continuous dynamic extraction at a fixed temperature of $50^{\circ} \mathrm{C}$ at $10.1,20.2$, and 30.4 MPa.

The samples and the standard (10 $\mu \mathrm{L}$ of $\mathrm{Cr}$ (1000 ppm), AAS standard) were irradiated by the nuclear reactor under identical conditions. The extraction efficiencies were calculated based on the radioactivities of $\gamma$-rays of metal ions found in the sample residues after SFE relative to those of standards. Triplicate runs of all SFE samples were undertaken in this study. The RSD between the samples is around $\pm 3-7 \%$. 


\section{Analytical procedures}

The quantities of $\mathrm{Cr}$ species from residues and trapping solutions were tested by neutron activation analysis. The filter paper or sand grains after extraction was placed in a small polyethylene vial and heat sealed for neutron irradiation. The amount of $\mathrm{Cr}$ complexes in the trapping solution was determined by transferring a known volume of the solution into small polyethylene vials. The chloroform-containing $\mathrm{Cr}$ species was then evaporated to dryness. The residue was redissolved in $0.5 \mathrm{~mL} \mathrm{50 \%} \mathrm{HNO}_{3}$, and then heat sealed for neutron irradiation. The samples, along with $10 \mu \mathrm{g}$ of standard in the same matrix, were irradiated simultaneously. After irradiation, the samples and standard were cooled down for 2 days before counting.

\section{Results and Discussion}

Extraction efficiencies of $\mathrm{Cr}$ species from sand and filter paper

Because of the reducing capability of dithiocarbamate ligands, the oxidation state of $\mathrm{Cr}(\mathrm{VI})$ species $\left(\mathrm{Cr}_{2} \mathrm{O}_{7}{ }^{2-}, \mathrm{CrO}_{4}{ }^{2-}\right)$ is reduced to trivalent state in the process of complex formation. ${ }^{4,5}$ To determine the concentrations of each $\mathrm{Cr}$ species in aqueous solutions, one first oxidizes $\mathrm{Cr}$ (III) by potassium permanganate $\left(\mathrm{KMnO}_{4}\right)$ followed by solvent extraction with dithiocarbamate ligands. ${ }^{6}$ The amount of $\mathrm{Cr}(\mathrm{III})$ is calculated from the difference in the concentrations between the aliquots, one with and one without oxidation. ${ }^{6}$ In an attempt to evaluate the feasibility of extracting $\mathrm{Cr}$ species from solid materials by $\mathrm{ScCO}_{2}$, we performed a series of experiments by spiking known amounts of $\mathrm{Cr}(\mathrm{III})$ and $\mathrm{Cr}(\mathrm{VI})$ on sand and filter paper.

$\mathrm{Cr}(\mathrm{III})$ species can be extracted by neat $\mathrm{CO}_{2}$ containing LiFDDC at $20.3 \mathrm{MPa}$ atm and $60^{\circ} \mathrm{C}$, with $10 \mathrm{~min}$ static extraction followed by $30 \mathrm{~min}$ of dynamic extraction. It was observed that extraction efficiencies of $\mathrm{Cr}$ (III) and $\mathrm{Cr}(\mathrm{VI})$ were higher in sand samples in comparison with those of filter paper samples. The extraction efficiencies of $\mathrm{Cr}$ (III) from sand and from filter paper were $46 \%$ and $35 \%$, respectively. This implies that the interactions between substrate and analytes are smaller in a silica matrix than in a cellulose matrix. Addition of a small amount of water $(10 \mu \mathrm{L})$ can increase extraction efficiencies of $\mathrm{Cr}(\mathrm{III})$ to $60 \%$ (sand) and $47 \%$ (filter paper), respectively. These results are very different from the known behavior of aqueous $\mathrm{Cr}(\mathrm{III})$ in conventional solvent extraction processes. The strong hydration of $\mathrm{Cr}$ (III) ion which prohibits the chelation of trivalent species with dithiocarbamate ligands in solvent extraction is no longer a problem in SFE. ${ }^{4,5}$ The extraction efficiencies of $\mathrm{Cr}(\mathrm{VI})$ by $\mathrm{ScCO}_{2}$ containing LiFDDC are higher than those observed from $\mathrm{Cr}$ (III) under similar conditions. For $\mathrm{Cr}(\mathrm{VI})$, the result indicates that when the samples were in dry form, extraction efficiencies were 64\% (sand) and $40 \%$ (filter paper), respectively. In the presence of water, the extraction efficiencies for $\mathrm{Cr}(\mathrm{VI})$ were raised to $72 \%$ and $67 \%$, respectively, for sand and filter paper samples.

Further study indicated that, in the presence of a small amount of water, using $5 \%$ methanol modified $\mathrm{CO}_{2}$ and LiFDDC as the extractant, the extraction efficiency tremendously increased to 92\% (sand) and 90\% (filter paper) for $\mathrm{Cr}$ (III), and 94\% (sand) and $92 \%$ (filter paper) for $\mathrm{Cr}(\mathrm{VI})$, respectively. These results are summarized in Table 1.

\section{Influence of water and methanol on extraction}

As shown in Table 1, in the presence of water, $\mathrm{Cr}$ (III) species spiked onto the solid substrates can be extracted nearly quantitatively. The presence of water facilitates the chelation and transport of metal complexes from solid matrices to the $\mathrm{CO}_{2}$
Table 1 Extraction efficiencies $(E, \%)$ of $\mathrm{Cr}(\mathrm{IIII})$ and $\mathrm{Cr}(\mathrm{VI})$ from solid matrices

\begin{tabular}{|c|c|c|c|c|c|}
\hline & \multirow{2}{*}{ Fluid phase } & \multicolumn{2}{|c|}{$\mathrm{Cr}(\mathrm{III})$} & \multicolumn{2}{|c|}{$\mathrm{Cr}(\mathrm{VI})$} \\
\hline & & (dry) & (wet) & (dry) & (wet) \\
\hline Sand & $\mathrm{CO}_{2}$ & 46 & 60 & 64 & 72 \\
\hline Filter paper & $\mathrm{CO}_{2}$ & 35 & 47 & 40 & 67 \\
\hline Sand & $5 \% \mathrm{MeOH}+\mathrm{CO}_{2}$ & 64 & 92 & 80 & 94 \\
\hline Filter paper & $5 \% \mathrm{MeOH}+\mathrm{CO}_{2}$ & 50 & 90 & 74 & 92 \\
\hline
\end{tabular}

Cr, $10 \mu \mathrm{g}(1000 \mathrm{ppm})$; sand, $200 \mathrm{mg}$; filter paper, $0.7 \times 2 \mathrm{~cm}^{2} ; 20.3$ $\mathrm{MPa}$ and $60^{\circ} \mathrm{C}, 10 \mathrm{~min}$ static time plus $30 \mathrm{~min}$ dynamic time; ligand, LiFDDC; average data from triplicate runs; RSD, $\pm 3-7 \%$; (wet) means a small amount of water is added onto the sample.

fluid phase. The water may also function as a modifier for solute/matrix interactions by blocking the active sites of the matrix via hydration, thus reducing the adsorption of the solute by the active sites of polar matrix. This result may reverse when more water was added. For instance, addition of $35 \mu \mathrm{L}$ water decreases the extraction efficiencies down to 5-10\%. This result is consistent with the phenomenon observed by Foy and Pacey. ${ }^{17}$ In their research, on addition of $20 \mu \mathrm{L}$ of $\mathrm{H}_{2} \mathrm{O}$, they found the extraction efficiency to be more than $80 \%$. However, when the amount of water was increased to $60 \mu \mathrm{L}$, the extraction efficiency dropped down to $40 \%$. Water at higher concentration is probably interfering with the $\mathrm{ScCO}_{2}$ fluid, which in turn influences the solubilities of the chelates and the metal complex. ${ }^{18}$ When water comes into contact with $\mathrm{CO}_{2}$, the $\mathrm{pH}$ value decreases due to the formation and dissociation of carbonic acid. For pressures between 7.1 and 20.3 MPa, and temperatures between 31.3 and $70^{\circ} \mathrm{C}$, the $\mathrm{pH}$ of water dissolved with $\mathrm{CO}_{2}$ was $2.9 .{ }^{22}$

The efficiency of extracting $\mathrm{Cr}(\mathrm{III})$ and $\mathrm{Cr}(\mathrm{VI})$ improved significantly when methanol was added to the fluid phase, especially for $\mathrm{Cr}(\mathrm{III})$. The enhanced extraction efficiencies are most likely due to increased interactions between the solutes and the modified fluid phase. Methanol plays an important role for increasing the polarity of $\mathrm{CO}_{2}$, thus facilitating the transportation of extracted solutes from solid matrices into the $\mathrm{CO}_{2}$ fluid phase. The extraction efficiencies of $\mathrm{Cr}$ ions, after the modification of 5\% methanol, can increase to more than $90 \%$, as shown in Table 1 . The change of solvent polarity by adding methanol with a small amount of water makes quantitative extraction of metal species into $\mathrm{ScCO}_{2}$ feasible.

\section{Optimization of the extraction}

In order to obtain optimal extraction conditions, further studies were undertaken. Figure 1 shows the extraction efficiencies of $\mathrm{Cr}$ (III) from filter paper using 5\% methanol modified $\mathrm{CO}_{2}$, when dynamic extraction time was fixed at 10 min, while the static extraction time was varied from 5 to 60 min. The results indicate that extraction efficiencies reached $90 \%$, and plateaued after 15 min of static extraction.

An investigation was also conducted at a fixed 10 min static extraction, by changing dynamic extraction times. The extraction efficiencies obtained were about $87 \%$ at $40 \mathrm{~min}$ and $90 \%$ at 60 min dynamic time, as shown in Fig. 2. Therefore, 20 min static extraction followed by 45 min dynamic extraction was chosen as standard extraction procedure in the consequent SFE experiments.

Both $\mathrm{Cr}(\mathrm{III})$ and $\mathrm{Cr}(\mathrm{VI})$ were extracted directly using $\mathrm{ScCO}_{2}$. In order to acquire quantitative extraction efficiencies, some 


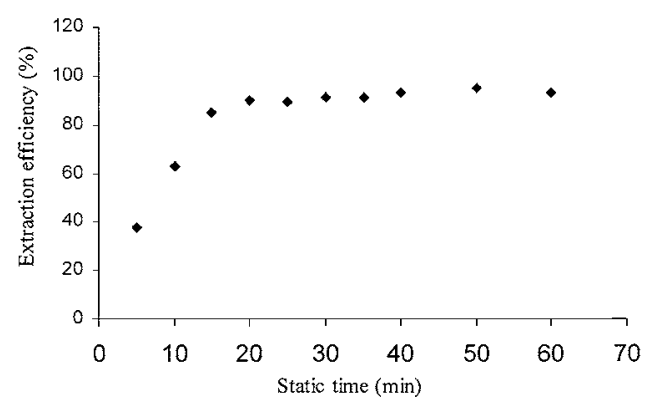

Fig. 1 Different static extraction times with a fixed dynamic time (10 min). Matrix: filter paper, 5\% methanol-modified $\mathrm{CO}_{2}$ with 10 $\mu \mathrm{L}$ water. RSD: $\pm 3-6 \%$.

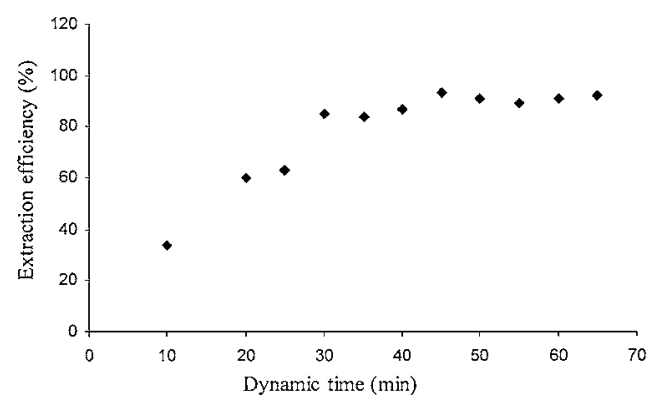

Fig. 2 Different dynamic extraction times with a fixed static time $(10 \mathrm{~min})$. Matrix: filter paper, $5 \%$ methanol-modified $\mathrm{CO}_{2}$ with 10 $\mu$ L water. RSD: $\pm 3-6 \%$.

modifications were undertaken. (1) Addition of methanol (5\% mole) to $\mathrm{CO}_{2}$ phase to change the polarity of the fluid phase and enhance the interactions between solute and solvent. (2) In the supercritical state, the solubilities of the chelating reagent and its complex are in proportion to the pressure (density) of the fluid $\left(\mathrm{ScCO}_{2}\right)$. When the density of $\mathrm{CO}_{2}$ increases with pressure, the solubilities of the solutes increase accordingly. A pressure of 25.3 MPa atm was chosen for further study. (3) At a fixed pressure, increase of temperature will decrease the density of $\mathrm{CO}_{2}$, thus reducing the solvating strength of the solvent $\left(\mathrm{ScCO}_{2}\right)$. The proper temperature $\left(50^{\circ} \mathrm{C}\right)$ was chosen based on this point of view. (4) Optimal extraction time, i.e., $20 \mathrm{~min}$ static extraction and 45 min dynamic extraction as discussed in the previous section, was selected for consequent SFE experiments. By applying these conditions, we significantly enhanced SFE efficiencies of $\mathrm{Cr}$ (III) to more than $92 \%$ in both silica and cellulose matrices.

The extraction efficiencies of chromium ions from sand and filter paper with neat $\mathrm{CO}_{2}$ in the absence of LiFDDC were insignificant $(<2 \%)$, indicating there is no organometallic species in the matrix. The amounts of $\mathrm{Cr}(\mathrm{III})$ and $\mathrm{Cr}(\mathrm{VI})$ spiked were at least one order of magnitude less than the solubility limit of LiFDDC in the fluid phase. ${ }^{23}$ Table 2 shows the extraction results for $\mathrm{Cr}(\mathrm{III})$ and $\mathrm{Cr}(\mathrm{VI})$ using these SFE conditions. In situ chelation/SFE provides a promising prosperity of extraction approach, in which $\mathrm{Cr}$ species including hydrated trivalent $\mathrm{Cr}$ ions can be quantitatively extracted into the $\mathrm{ScCO}_{2}$ phase.

\section{Application of in-situ/chelation SFE on environmental sample}

In order to evaluate the feasibility of this in situ chelation/SFE method, we used wood samples to verify our methodology. The
Table 2 Extraction efficiencies $(E, \%)$ of $\mathrm{Cr}(\mathrm{III})$ and $\mathrm{Cr}(\mathrm{VI})$ from solid matrices under optimal conditions

\begin{tabular}{lclcc}
\hline \multicolumn{1}{c}{ Fluid phase } & $\begin{array}{c}\text { Ligand } \\
\text { amount/mg }\end{array}$ & \multicolumn{1}{c}{ Matrix } & $\begin{array}{c}E, \% \\
(\mathrm{Cr}(\mathrm{III}))\end{array}$ & $\begin{array}{c}E, \% \\
(\mathrm{Cr}(\mathrm{VI}))\end{array}$ \\
\hline $\mathrm{CO}_{2}$ & - & Sand (wet) & $<1$ & $<2$ \\
$\mathrm{CO}_{2}$ & 50 & Sand (wet) & 78 & 88 \\
$\mathrm{CO}_{2}$ & 50 & Filter paper (wet) & 59 & 79 \\
$\mathrm{CO}_{2}+5 \% \mathrm{MeOH}$ & 50 & Sand (wet) & 95 & 96 \\
$\mathrm{CO}_{2}+5 \% \mathrm{MeOH}$ & 50 & Filter paper (wet) & 92 & 94 \\
\hline
\end{tabular}

$\mathrm{Cr}(\mathrm{III})$ or $\mathrm{Cr}(\mathrm{VI}), 10 \mu \mathrm{g}$; sand, $200 \mathrm{mg}$; filter paper, $0.7 \times 2 \mathrm{~cm}^{2} ; 5 \%$ $\mathrm{MeOH} / \mathrm{CO}_{2} ; 25.3 \mathrm{MPa}$ and $50^{\circ} \mathrm{C}, 20 \mathrm{~min}$ static time plus $45 \mathrm{~min}$ dynamic time; ligand, LiFDDC; analyzed by NAA; triplicate runs; RSD, $\pm 4-6 \%$.

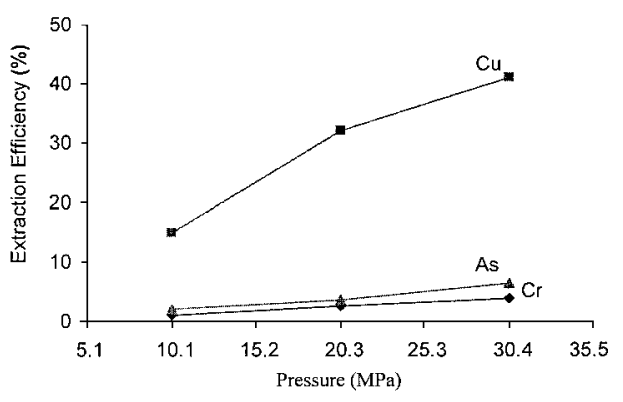

Fig. 3 Extraction efficiencies of $\mathrm{Cr}$ from wood sample treated with CCA at different pressures using dynamic extraction by pumping 0.1 $\mathrm{M} \mathrm{LiFDDC} / \mathrm{MeOH}$ in $\mathrm{CO}_{2}$ phase, at $20.3 \mathrm{PMa}$ and $50^{\circ} \mathrm{C}$. Wood sample $50 \mathrm{mg}$, extraction percentage is calculated from the final concentration of metal ions in accumulated trap solutions divided by the concentration of metals in wood before SFE.

concentration of metal ions in CCA-treated wood varies depending on the specific purpose of the lumber and manufacturer formulation of the CCA solution. Because dithiocarbamate ligand is less stable in the weak acidic medium, excess amounts of this ligand are usually used. LiFDDC $(0.1 \mathrm{M})$ was prepared in methanol solution, and delivered into the high pressure SFE system via a HPLC pump. As can be seen in Fig. 3, when we used $0.1 \mathrm{M}$ of $\mathrm{LiFDDC} / \mathrm{MeOH}$ solution in $\mathrm{ScCO}_{2}$, about $2.5 \% \mathrm{Cr}$ species was removed at $20.3 \mathrm{MPa}$ and $50^{\circ} \mathrm{C}$ by cumulative dynamic extraction in $2 \mathrm{~h}$, and finally $455 \mu \mathrm{g} \mathrm{Cr} / \mathrm{g}$ wood waste was removed. The extraction efficiency for this sample was below our expectation. This is probably due to the following reasons. The chromium species in the wood sample can be in different chemical forms and oxidation states, and they are not readily extracted under the experimental conditions used. The chemistry in matrices of the real samples is different from that of spiked samples. In addition, dithiocarbamate derivatives are less stable in an acidic medium. The $\mathrm{pH}$ of $\mathrm{ScCO}_{2}$ is around 2.9; which may accelerate the decomposition of dithiocarbamate derivatives in SFE processes. ${ }^{22}$

In SFE of $\mathrm{Cr}$ in CCA-treated wood, both $\mathrm{Cu}$ and As species are also involved. The SFE profiles of copper and As species are shown in Fig. 3 as well. We understand that both $\mathrm{Cr}$ and $\mathrm{As}$ species could be in the different oxidation states. Divalent $\mathrm{Cu}$ cations probably compose the majority of the species of $\mathrm{Cu}$ existing in the matrix. The extractions of $\mathrm{Cu}$ are much higher than those of $\mathrm{Cr}$ and As. At $30.4 \mathrm{MPa}$, in the first $15 \mathrm{~min}$, about $510 \mu \mathrm{g} / \mathrm{g}$ of $\mathrm{Cr}$ was extracted from the wood sample, which was equivalent to about $26 \mu \mathrm{g}$ of $\mathrm{Cr}$ in the $50 \mathrm{mg}$ wood sample. 
Within $2 \mathrm{~h}$, the trap samples were collected cumulatively from the same wood sample and the amount of $\mathrm{Cr}$ can be removed up to 680,455 , and $175 \mu \mathrm{g} / \mathrm{g}$ totally at $30.4,20.3$, and $10.1 \mathrm{MPa}$, respectively. Most leachable $\mathrm{Cr}$ ions can be removed from the wood matrix in the first $45 \mathrm{~min}$. After that the extraction curve gradually approached a plateau (not shown). The efficiencies of SFE are pressure dependent. For example, at $30.4 \mathrm{MPa}$, about $4 \%$ of $\mathrm{Cr}$ could be extracted, while at $10.1 \mathrm{MPa}$, the extraction efficiency of $\mathrm{Cr}$ was $1 \%$ in $2 \mathrm{~h}$ extraction time, as shown in Fig. 3. The unleachable fraction of $\mathrm{Cr}$ species could be in different oxidation states and may strongly bind to the native ligands in matrices, thus making the SFE difficult.

\section{Conclusions}

Extractions of $\mathrm{Cr}$ (III) and $\mathrm{Cr}(\mathrm{VI})$ metal ions from solid matrices can be accomplished directly using $\mathrm{ScCO}_{2}$ containing LiFDDC. Chromium ions spiked on the silica and cellulose matrices can be effectively extracted by in situ chelation/SFE in the presence of a small amount of water. Methanol can significantly improve the extraction efficiency of $\mathrm{Cr}$. Trivalent $\mathrm{Cr}$ ions can be extracted completely under optimal SFE conditions, though they are not extractable by traditional solvent extraction methods. In real wood samples which contain CCA, Cr(III) and $\mathrm{Cr}(\mathrm{VI})$ species can be extracted by LiFDDC in $\mathrm{ScCO}_{2}$. The extracted $\mathrm{Cr}$ species in environmetal samples represents the leachable portion in which their oxidation states and the matrix effect are different from the spiked samples. With the aid of a small amount of water in metahol modified $\mathrm{CO}_{2}$, in situ chelation/SFE technique provides a better approach and potential industrial applications for the removal of toxic $\mathrm{Cr}$ from environmental matrices in the field of decontamination of heavy metal containing wastes.

\section{Acknowledgements}

This research was supported by the Center for Hazardous Waste Remediation Research of the University of Idaho.

\section{References}

1. S. Matsuoka, Y. Nakatsu, K. Takehara, S. Saputro, and K. Yoshimura, Anal. Sci., 2006, 22, 1519.

2. N. P. Vela, L. K. Olson, and J. A. Caruso, Anal. Chem., 1993, 65, 585A.

3. T. Tande, J. E. Pettersen, and T. Torgrimsen, Chromatographia, 1980, 13(10), 607.

4. K. S. Subramanian, Anal. Chem., 1988, 60, 11.

5. J. S. Wang and K. H. Chiu, Anal. Sci., 2004, 20, 841.

6. U. S. EPA, "Methods for Chemcial Analysis of Waters and Wastes", 1983, Cincinnati, OH.

7. M. Ashraf-Khorassani, J. W. Hellgeth, and L. T. Taylor, Anal. Chem., 1987, 59, 2077.

8. J. M. Hope, R. L. Martin, D. Taylor, and A. H. White, $J$. Chem. Soc., Chem. Commun., 1977, 3, 99.

9. G. Schwedt, Fresenius Z. Anal. Chem., 1979, 295, 382.

10. L. J. Mulcahey and L. T. Taylor, Anal. Chem., 1992, 64, 981.

11. J. W. Hills, H. H. Hill, and T. Maeda, Anal. Chem., 1991, 63, 2152.

12. S. B. Hawthorne, D. J. Miller, D. E. Nivens, and D. C. White, Anal. Chem., 1992, 64, 405.

13. K. E. Laintz, C. M. Wai, C. R. Yonker, and R. D. Smith, Anal. Chem., 1992, 64, 2875.

14. C. M. Wai and S. F. Wang, J. Chromatogr., A, 1997, 785, 369.

15. C. M. Wai, S. Wang, Y. Lin, V. Lopez-Avila, and W. F. Beckert, Talanta, 1996, 43, 2083.

16. C. Zhaojie, G. Y. Zhang, S. Wei, and S. Yuntao, J. Liq. Chromatogr. Relat. Technol., 2004, 27(6), 985.

17. G. P. Foy and G. E. Pacey, Talanta, 2000, 51, 339.

18. C. Kersch, G. F. Woerlee, and G. J. Witkamp, Ind. Eng. Chem. Res., 2004, 43, 190.

19. V. Arancibia, M. Valderrama, K. Silva, and T. Tapia, J. Chromatogr., B, 2003, 785, 303.

20. L. Sucre and W. Jenning, Anal. Lett., 1980, 13(A6), 497.

21. W. M. Mok and C. M. Wai, Anal. Chem., 1987, 59, 233.

22. K. L. Toews, R. M. Scroll, C. M. Wai, and N. G. Smart, Anal. Chem., 1995, 67, 4040.

23. K. E. Laintz, C. M. Wai, C. R. Yonker, and R. D. Smith, J. Supercrit. Fluids, 1991, 4(3), 194. 